\title{
Absence of surface flaking in hierarchical glass-ceramic coating: high impact resistant ceramic tiles
}

\author{
E. Enríquez ${ }^{\star 1,2}$, V. Fuertes ${ }^{1}$, M.J. Cabrera², Jaime Seores² $^{2}$ D. Muñoz² J. F. Fernández ${ }^{1}$ \\ 1Dept. Electrocerámica, Instituto de Cerámica y Vidrio, CSIC, Kelsen 5, 28049, Madrid, Spain. \\ ${ }^{2}$ Centro tecnológico Vidres, S.L., Ctra. Onda, Km 3.4, 12540 Villareal, Castellón, Spain
}

\begin{abstract}
The impact resistance method is a useful procedure to determine the tile resistance. While other works are focused on modifying the tile support to improve the impact resistance, in this work, a new glass-ceramic material was developed to used it as glaze coating in order to relax impact tensions. This material possesses a hierarchical nano-microstructure consisted of microcrystal surrounded by nanostructured regions having low glassy phase, which is considered responsible for tension relaxations. The resilience coefficient measured in conventional and glass-ceramic glazes presents little differences (0.85-0.88). However, impact damages on the surface is totally inhibited for glass-ceramic coating while the conventional one suffers great flaking. These damages were analyzed by Optical profilometry and FESEM to compare the impact resistance and to correlate it with its microstructure. The results confirm that the micro-nanostructured coating paves the way to improve impact resistance in ceramic materials where surface damage is a critical parameter.
\end{abstract}

\footnotetext{
*Corresponding author. Tlf:+34 9173558 40; Ext 1076. Fax: +34 9173558 43. E-mail address: esther@icv.csic.es (E. Enríquez)
} 


\section{Impact resistance}

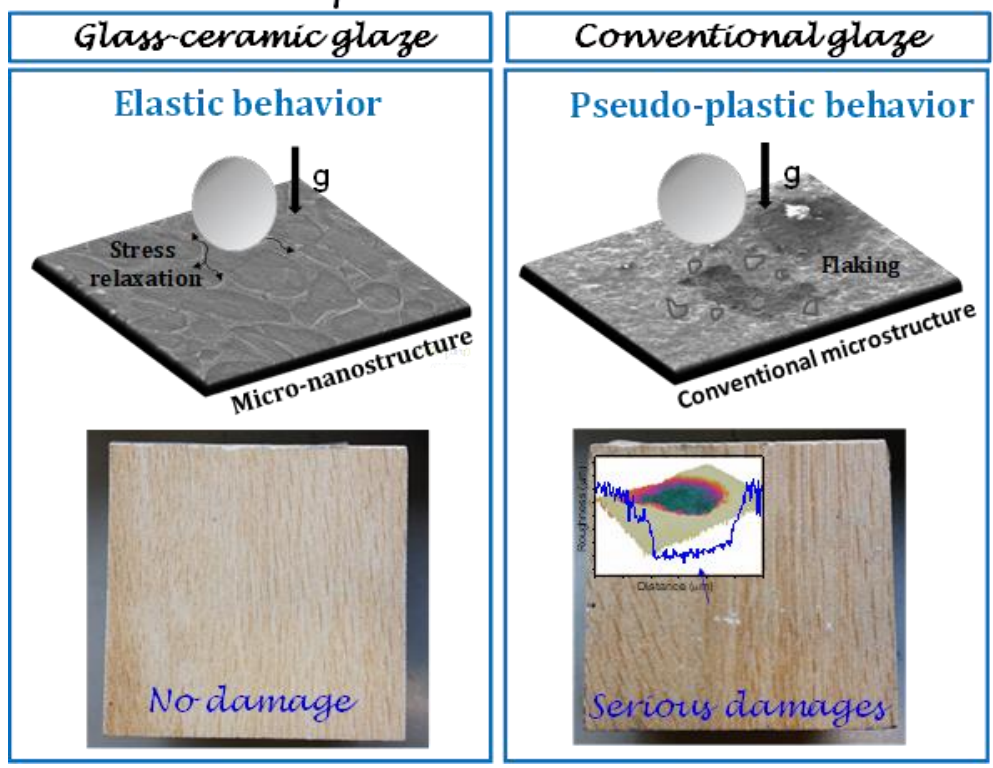

Keywords: Impact resistance; glass-ceramic; nano-microstructure; elastic behavior.

\section{Introduction}

Ceramic materials have excellent durability properties that make them suitable for application as building materials. One of the most critical aspects at present, consists in their low impact resistance, since they have good mechanical properties but they are brittle. In particular, for ceramic tile floors, the fall of a heavy object can cause the appearance of surface flaking. Moreover, the new manufacturing trends in ceramic tiles having enlarge sizes and low thickness, further complicates this problem, because it is well-known that the impact resistance strongly depends on the tile thickness, being more resistant as larger the thickness is. In fact, the British standard 1281:1966, stablishes the dropped height of the Steel ball (that is, the energy) appropriate for different glaze thicknesses [1,2]. The resistance to impact has been significantly improved in ceramic materials for armoring, where pre-stressed materials have been developed and composite materials with laminated and gradient composition using structural ceramics [3,4]. Improved glassceramic materials were also proposed for transparent armor applications [5].

These new requirements of the ceramic trade, make it necessary to improve the impact resistance response. The impact resistance method provides the coefficient of restitution which gives information about the inelastic deformation of the material. This coefficient is usually related with the surface damage produced by the ball impact. The impact resistance mainly depends on the internal tension, superficial cracks, critical defects, the thickness and porosity of the material $[6,7]$. In this context, previous researches are focused on improving the impact resistance by adding $\mathrm{Al}_{2} \mathrm{O}_{3}$ particles [8,9], using microwave energy for the ceramic tiles processing [10], imitating layered 
structures observed in natural elements [11] or adding metallic nickel inclusions in a ceramic matrix [12]. Thus, most of the approaches are focused on improving mechanical properties of the ceramic tile body. It is also proposed to remove glaze coating for improving mechanical properties of ceramic tiles, since it is the most brittle layer [6]. In some cases, due to the difficulty of avoiding surface damages, new solutions have even been proposed, such as decorate the tile in bulk in order to hide flaking or cracks that can be produced by a collision.

In previous works, a glass-ceramic glaze based on Na-rich plagioclase has been developed, presenting a unique nano-microstructure $[13,14]$, which improves glaze mechanical properties achieving excellent tribological properties, flexural strength and hardness response $[15,16]$. Consequently, in this work, two kind of samples were studied, a conventional tile (stoneware support, engobe and glassy glaze) and a novel tile where the glassy glaze has been substituted by this new engineered material, maintaining the conventional stoneware support and engobe, in order to improve impact resistance without the necessity of increasing its thickness. The difference observed in the impact damages are then correlated with the different composition, microstructure and properties of both samples, demonstrating the effectiveness of the glass-ceramic glaze.

\section{Experimental procedure}

\subsection{Sample preparation}

The glass-ceramic glaze based on Na-rich plagioclase feldspar was prepared by mixing the precursors, kaolin (Molcasa, $d_{50}=5.34 \mu \mathrm{m}$ ) and frit in a weight proportion of 10/90, respectively, with a milling process in an alumina ball mill for 20 min with $37 \mathrm{wt} \%$ of water [13], following the standard ceramic processing for the tile industry. In addition, a standard commercial glaze was also used for comparative purposes. Both materials were deposited on the same kind of porcelain stoneware support of $\sim 1 \mathrm{~cm}$ in thickness, through water falling deposition process and were thermally treated at $1220^{\circ} \mathrm{C}-6 \mathrm{~min}$ through a fast sintering process. In addition, an engobe layer of $\sim 90 \mu \mathrm{m}$ of thickness was deposited between the glaze and support in order to avoid dilatation and diffusion problems. The chemical composition of glass-ceramic and conventional glazes, expressed in terms of equivalent oxides, are showed in Table 1. The crystalline phases of samples can be extracted from the XRD patterns shown in figure 1, where it is possible to observe that glass-ceramic glaze is composed of Na-rich plagioclase and quartz, and conventional glaze is composed of quartz, zircon and bytownite (a calcium rich member of the plagioclase solid solution series of feldspar). The glassy phase of the conventional ( $56 \%$ ) and the Na-rich plagioclase glass-ceramic ( $\sim \%$ ) glazes was calculated from the broad band located between $15^{\circ}$ and $35^{\circ}$ in 
the XRD patterns by means of the diffraction software Bruker's Diffrac. Eva. The porosity of samples is $8.3 \%$ and $3.1 \%$ for conventional and glass-ceramic glazes, respectively. In order to determine the roughness contribution to the impact resistance, a feldspar granulate was deposited on the top of the glass-ceramic glaze before sintering. Moreover, samples were decorated with wood motives by using inkjet printing, in such a way that, when damage occurs, this decorative coating is removed, leaving a more obvious imprint. Nevertheless, the images of the damage caused to undecorated samples can be seen in figure S2 of supporting information.

\begin{tabular}{c|cc} 
Oxides wt \% & Na-rich plagioclase & Conventional \\
\hline $\mathrm{SiO}_{2}$ & 51.63 & 43.70 \\
$\mathrm{ZrO}_{2}$ & - & 4.07 \\
$\mathrm{SrO}$ & 8.05 & 3.28 \\
$\mathrm{Na}_{2} \mathrm{O}$ & 2.68 & 1.50 \\
$\mathrm{~K}_{2} \mathrm{O}$ & 1.46 & 1.52 \\
$\mathrm{Al}_{2} \mathrm{O}_{3}$ & 21.14 & 32.20 \\
$\mathrm{ZnO}$ & 1.10 & 2.14 \\
$\mathrm{CaO}$ & 10.47 & 2.98 \\
$\mathrm{~B}_{2} \mathrm{O}_{3}$ & 1.40 & 1.50 \\
$\mathrm{P}_{2} \mathrm{O}_{5}$ & 0.84 & 2.88 \\
$\mathrm{MgO}$ & 1.04 & 1.63 \\
$\mathrm{BaO}$ & - & 2.12 \\
Others & 0.21 & -
\end{tabular}

Table 1. Chemical composition of the Na-rich plagioclase glass-ceramic material and conventional glaze, expressed as equivalent oxides. The minority components ( $<1 \mathrm{wt} \%)$ are all included in others. *Others: mainly $\mathrm{TiO}_{2}$ and $\mathrm{Fe}_{2} \mathrm{O}_{3}$. 


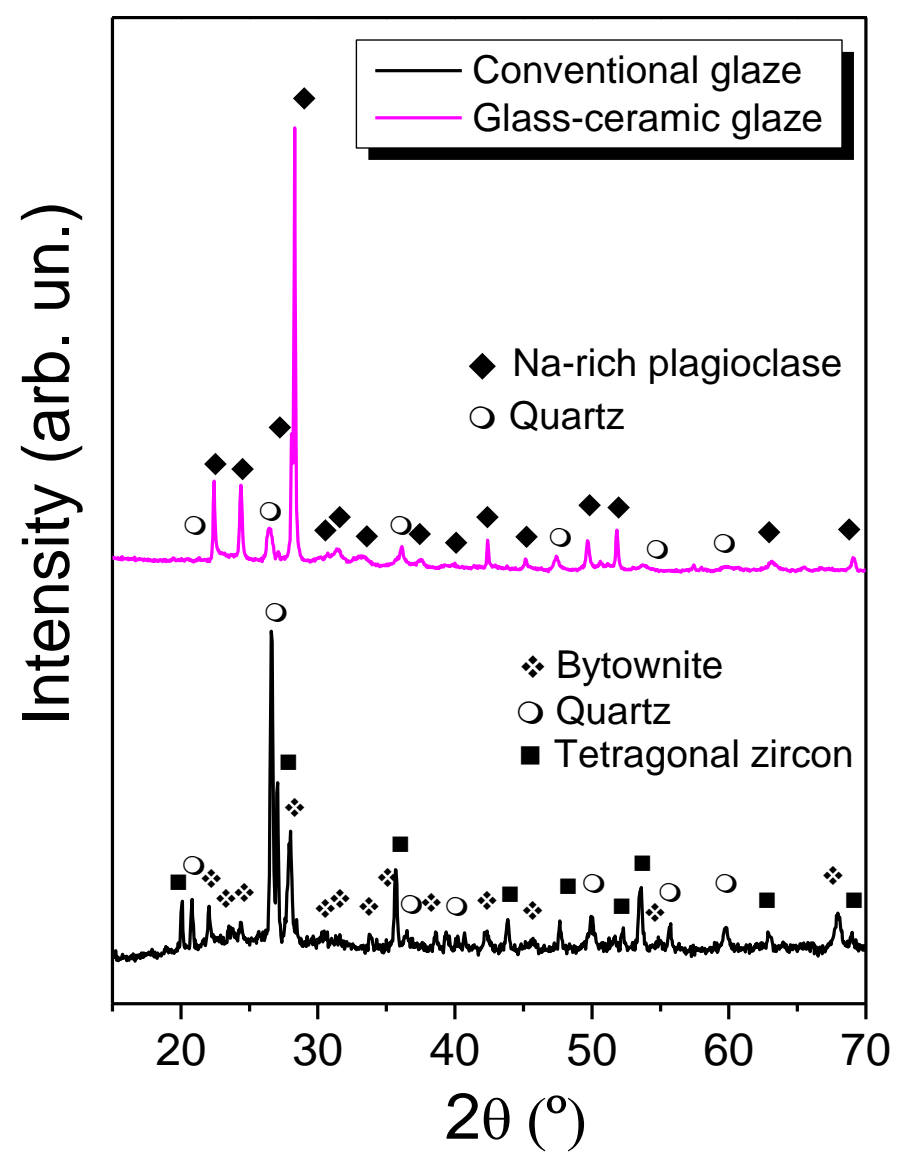

Figure 1: XRD pattern for Na-rich plagioclase glass-ceramic glaze and conventional glaze studied in this work.

\subsection{Characterization}

Chemical composition characterization was carried out by a X-Ray Fluorescence Spectrometer (Philips MagiX, equipped with a rhodium $\mathrm{x}$-ray tube and beryllium window). The structural characterization of samples was performed by X-ray diffraction (XRD) in a diffractometer Bruker D8 Advance with Cu Ka radiation, $40 \mathrm{kV}$ and $40 \mathrm{~mA}$ and the crystalline phases identification was carried out by comparison with JCPDS patterns. The glassy phase content was calculated through the areas integration by means of the diffraction software Bruker's Diffrac.Eva.

Impact test was carried out by Gabtec impact tower with a steel ball of $19.00 \pm 0.05 \mathrm{~mm}$ in diameter, following the normative ISO 10545 [17], which is based on the rebound of the ball dropped from a height of $120 \mathrm{~cm}$ onto a tile fixed in a mortar support of $6 \mathrm{~cm}$ of thickness, applying weak impact 
energy $(0.27 \mathrm{~J})$. A ceramic standard provided by the supplier was used for calibration. Samples should be of $75 \mathrm{~mm} \times 75 \mathrm{~mm}$ dimensions and the measurements should be repeated for 5 specimens of each. This technique provides the coefficient of restitution (e) of studied materials, which gives information of the inelastic deformation of the material. That is, when $e=0$, the collision between two materials is considered completely inelastic, and when $\mathrm{e}=1$, the collision is elastic (all the energy is conserved). However, this method does not measure the damage produced in the ceramic tiles after impact. For this purpose, ZETA-20 Multi-mode Optical Profiler was used to register the surface profile of the impact imprints of damaged samples. According to the French Standard 3515 of CSTB for glazed tiles, the surface damage can be classified into different levels:

- Level 0: None visible damage on the tile surface.

- Level 1: Circular lines around the impact. No radial cracks or flaking of material.

- Level 2: Radial cracks of $\mathrm{I} \leq 5 \mathrm{~mm}$ in length. No flaking of material.

- Level 3: Radial cracks of $5<1 \leq 10 \mathrm{~mm}$. No flaking of material.

- Level 4: Radial cracks of $\mathrm{I}>10 \mathrm{~mm}$. No flaking of material.

- Level 5: Flaking of material.

The combination of both parameters, allow us to relate the resilient coefficient with the surface damage. In addition, microstructural characterization of samples was studied by means of Field Emission Scanning Electron Microscopy (FESEM) using a Hitachi S-4700, with a resolution of 1.5 $\mathrm{nm}$ at $20 \mathrm{kV}$.

\section{Results and discussion}

\subsection{Microstructure of the studied glazes}

Figure 2 shows the FE-SEM micrographs of conventional (figures $2 a$ and $d$ ) and glass-ceramic (figures $2 b$ and e) glazes, and of the granulated layer onto glass-ceramic glaze (figures $2 c$ and f). Figures $2 a, b$ and $c$ show the distribution of the glazed and engobe layers and the stoneware support of each sample, where it is possible to extract the thickness of each one, which are in the range of $270-300 \mu \mathrm{m}$ for glazes and $70-100 \mu$ for engobe. In addition, in these figures, it is possible to verify the interface between the three layers, where it is observed that a correct match is produced between support-engobe and engobe-glaze, since no curvature or decoupling is produced. Moreover, the thermal expansion coefficient of both samples are very similar, $53 \cdot 10^{-7}$ ${ }^{\circ} \mathrm{C}^{-1}$ for glass-ceramic glaze and $56 \cdot 10^{-7}{ }^{\circ} \mathrm{C}-1$ for conventional glaze, which match well with the engobe and the stoneware, that have thermal expansion of $70.8 \cdot 10^{-7}{ }^{\circ} \mathrm{C}^{-1}$ and $70.4 \cdot 10^{-7}{ }^{\circ} \mathrm{C}-1$, respectively. Glazes should have slightly lower thermal expansion coefficient than the support, that 
results in a slight compression of the glaze layer during the sintering. This fact improved the mechanical strength response of the glaze. However, the ceramic tile has a high planarity which indicates a low effect of the glaze on the support according to the requirements of the ceramic product. Conventional glaze presents a microstructure composed of elongated anorthite feldspars (up to $17 \mu \mathrm{m}$ ) along with quartz and zircon crystals, as seen in figure $2 \mathrm{~d}$. In addition, large amount of glassy phase is also observed. In the case of glass-ceramic glaze, it shows a dual nanomicrostructure formed by Na-rich plagioclase microcrystals of up to $3 \mu \mathrm{m}$ in length, surrounded by nanocrystals of the same material that provides a hierarchical micro-nanostructure (figure 2e). In this case, the glassy phase is located in the nanostructured region, and is much lower than in the conventional glaze. The granulates onto the glass-ceramic glaze form hillocks of up to $100 \mu \mathrm{m}$, as seen in figure $2 \mathrm{c}$, making the surface rougher. The granulated microstructure is formed by elongated feldspars microcrystals of $\approx 12 \mu \mathrm{m}$ in length (figure $2 \mathrm{f}$ ).
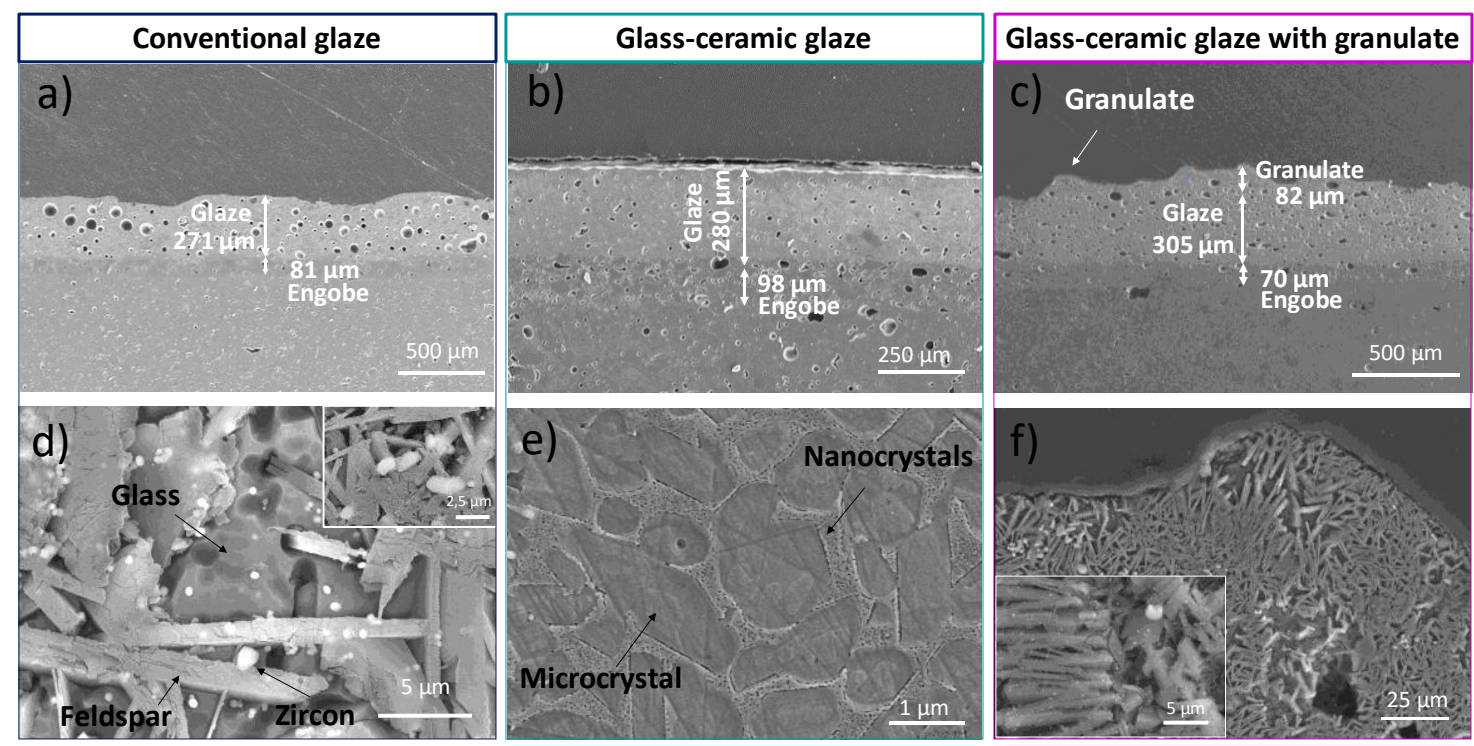

Figure 2: FE-SEM micrographs of conventional ( $a$ and $\mathbf{d}$ ) and hierarchical glass-ceramic ( $b$ and $\mathbf{e}$ ) glazes; granulate deposited onto glass-ceramic glaze surface (c and f).

\subsection{Impact resistance test of glazes}

The impact resistance test was carried out for the three samples and Table 2 shows the resilience coefficients along with the average roughness values. Roughness of conventional and glassceramic glazes are similar, but when granulates are deposited, roughness increases up to 40 times. The resilience coefficient values obtained are typical of stoneware tiles [2,18-20]. The hierarchical glass-ceramic glaze has a slightly larger resilience coefficient than the conventional one, however, 
they are very similar, indicating that the resilience of the tile depends more on the whole system (glaze-engobe-stoneware) than on the surface coating. That is, since the distribution of layers are the same, with similar thicknesses and the same composition for the support and the engobe, and, in addition, the interfaces of both samples are correctly matched, the average calculation of the resilient coefficient is similar. However, the glaze with granulates deposited onto the surface of the glass-ceramic coating, worsen its value showing that the surface roughness affects negatively the impact resistant, because it absorbs inhomogeneously the impact and concentrated the stress at the protruded regions. Therefore, from these results it is inferred that, in the same surface conditions, the resilience coefficient is more influenced by the bulk composition than by the surface coating.

\begin{tabular}{c|c|c|c|}
\multirow{2}{*}{ Glaze coating } & $\begin{array}{c}\text { Average surface } \\
\text { roughness }(\boldsymbol{\mu m})\end{array}$ & $\begin{array}{c}\text { Average resilience } \\
\text { coefficient }\end{array}$ & Damage marks \\
\hline \begin{tabular}{c} 
Conventional \\
Hierarchical glass - \\
ceramic glaze \\
\cline { 2 - 4 } $\begin{array}{c}\text { Hierarchical granulated } \\
\text { glass-ceramic glaze }\end{array}$
\end{tabular} & $17.9 \pm 0.5$ & $0.85 \pm 0.02$ & Yes \\
\cline { 2 - 4 } & $52.2 \pm 0.5$ & $0.88 \pm 0.02$ & Yes \\
\hline
\end{tabular}

Table 2: Resilience coefficient of the conventional, hierarchically glass-ceramic and granulated glass-ceramic glazes, obtained by the impact resistant test.

On the other hand, it is also important to point out that, in this case, the damage produced by the ball impact is not clearly correlated with the resilience coefficient, since despite they have similar coefficient, conventional and glass-ceramic coatings present different surface damage degree. Figure 3 shows the images of the white glazes after the impact test (figures $3 a$ and $b$ ) and the optical images when a dye (methylene blue) is used to highlight the damage (figures $3 c, 3 d, 3 e$, and $3 \mathrm{f})$. As can be seen, conventional glaze undergoes severe damage with material flaking (level 5 according French Standard). The dye clearly reveals the ball impacts (figure $3 c$ ) which are more pronounced on the first rebound, and smaller on the seconds. Figure $3 e$ shows an enlargement of the main damage where it is possible to observe that the glaze has been removed leaving a hole of more than $2000 \mu \mathrm{m}$ in length. However, the glass-ceramic glaze does not present any damage (figure $3 b$ ) and when the dye is used (figure $3 d$ ), only a slight glaze coloring is produced, but not damages are revealed. The enlarged optical image (figure $3 f$ ) confirms these results, since a 
homogeneous surface is observed. The optical images of the decorated granulated glass-ceramic glaze when a dye is used to reveal de damages, can be seen in figure $\mathrm{S} 1$ of supporting information.

It is known, that the energy lost in the impact is related with the number and size of the flaky fragments [21]. In this case, the initial impact energy is low $(0.27 \mathrm{~J})$ and the damage and flaky material is a very low proportion regarding the whole system (glaze - engobe - support). Therefore, the energy lost during the impact, which causes the flaking in the case of the conventional tile, is very low and does not significantly affect the ball rebound, resulting in no significant differences in the resilience coefficient. Nevertheless, the difference detected might be due to these energy differences. It is worth to remark the total absence of damage marks in the tile where the hierarchical glass-ceramic material is used as coating, which would classify it as level 0 in damage regarding the French Standard 3515 of CSTB. This result is unusual because, up to know, the appearance of surface flaking is inherent to the brittle behavior of conventional glaze coating for stoneware tiles.

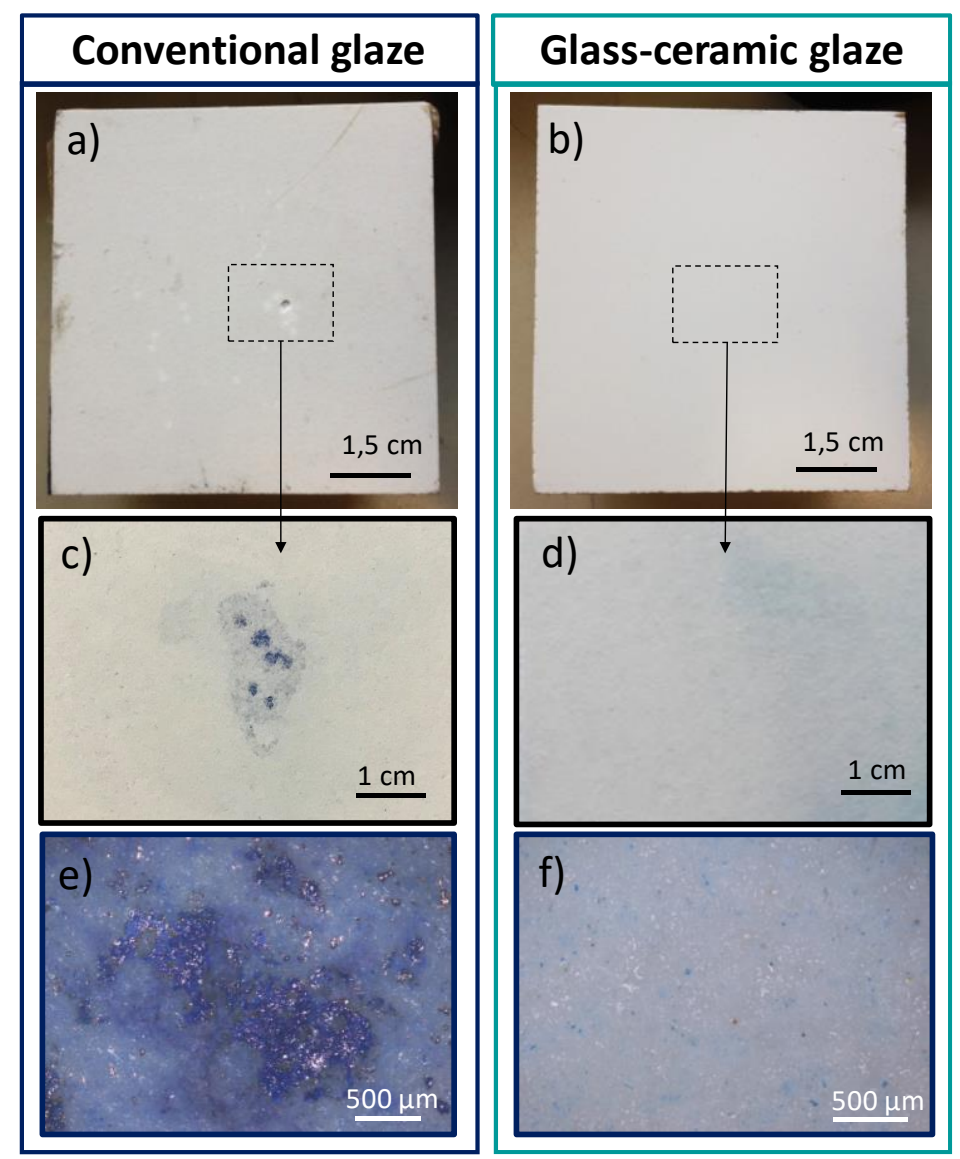

Figure 3: Images taken after impact test and optical images taken when a dye is used to reveal the damages in white conventional (a, c and $\mathbf{e})$ and white hierarchical glass-ceramic (b, $\mathbf{d}$ and f) glazes, where it is possible to check the damage produced by the steel ball. 
Figure 4 shows the images and the FESEM micrographs of conventional glaze (figures $3 a$ and $3 d$ ), hierarchical glass-ceramic glaze (figures $3 \mathrm{~b}$ and $3 \mathrm{e}$ ) and granulated glass-ceramic glaze (figures $3 c$ and $3 f$ ) with decorative motives, after the impact resistance test, where it is also possible to check the damage caused by the steel ball because of the contrast produced by the lack of decoration in the damage. The green and blue squares shown in the FESEM micrographs (figures $3 d$ and $3 f$ ) represent the regions where a further analysis of the damage produced was carried out and will be shown later.

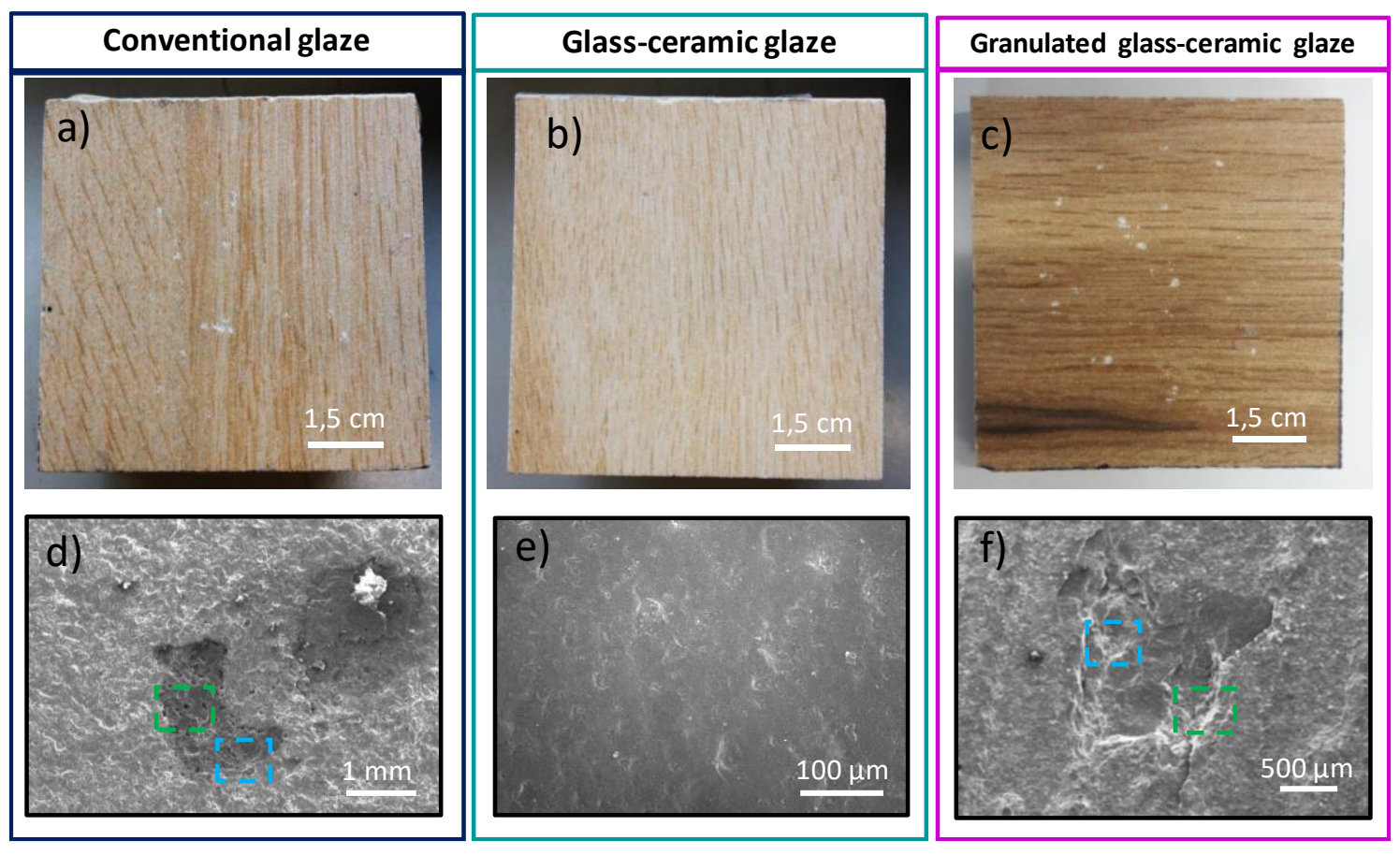

Figure 4: Images and FESEM micrographs of conventional (a and $d$ ), hierarchical glassceramic ( $\mathbf{b}$ and $\mathbf{e}$ ) and granulated glass-ceramic (c and $\mathbf{f}$ ) glazes with decorative motives, after the impact resistance test, where it is possible to check the damage produced by the steel ball. The green and blue squares represent the regions where a further analysis of the damage produced was carried out.

Decorated conventional glaze coatings (figure 4a) are highly damaged and present abundant surface flaking (level 5 according French Standard) and shallower marks (level 1), produced by the successive ball impacts. It is clearly shown that the decoration has been removed by the impacts, leaving white enamel marks. However, in case of the hierarchical glass-ceramic coating, there is an absence of surface flaking and marks (level 0 ) (figure $4 \mathrm{~b}$ ), as occurred in the white glaze. The addition of granulates onto the glass-ceramic coating produces damage by the ball impact although 
the sizes of the marks are smaller than the ones produced in the conventional coating (figure 4c). The damages are studied in more detail in the FESEM micrographs. Figure $4 \mathrm{e}$ shows that the glass-ceramic coating has a homogeneous surface. Figure $4 \mathrm{~d}$ shows the micrograph of the impact damages produced in the conventional glaze. There are observed two impact types, one more pronounced corresponding to the first impact, and other less significant, corresponding to secondary rebounds. The main surface flacking is $\approx 2300 \mu \mathrm{m}$ in width. Figure $4 \mathrm{f}$ shows the main surface flaking caused by the ball impact on granulated glass-ceramic coating, where a short crack can be observed (lower than $5 \mathrm{~mm}$, which corresponds to level 2 in French Standard), indicating the impact stress. The size of this damage is lower than in the conventional coating, being $\approx 1300$ $\mu \mathrm{m}$ in width $(\approx 50 \%$ lower). The green and blue squares represent the regions where a further analysis of the damage produced was carried out, which can be seen in figure 5 , where a comparison of the damage in conventional and granulated glass-ceramic glazes is performed.

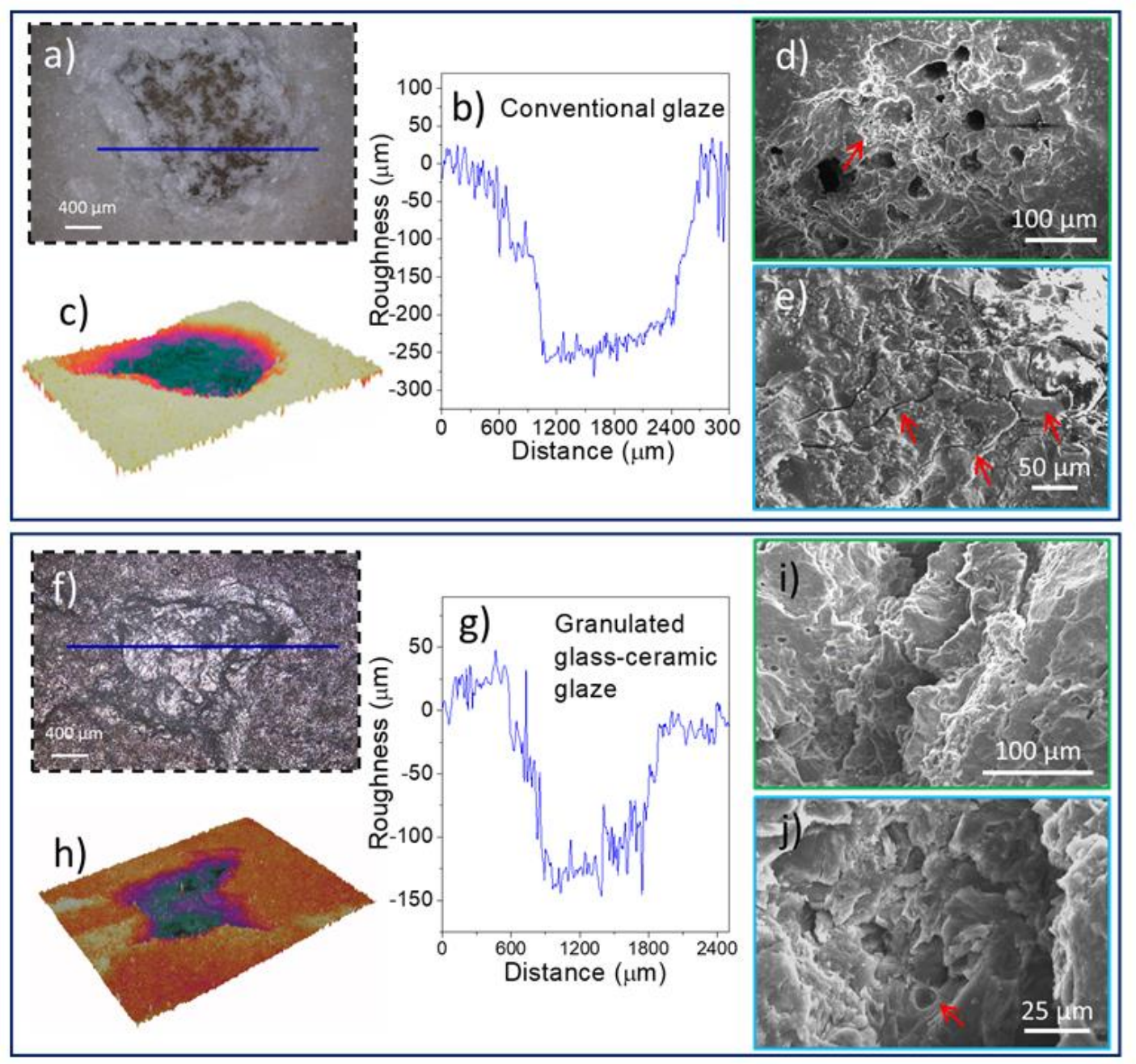

Figure 5: Damage produced by the ball impact into glazes: Optical image of the main hole generated by the ball during impact test for a) conventional and f) granulate onto glass-ceramics 
glazes; hole profile for $\mathbf{b})$ conventional and $\mathbf{g}$ ) granulate onto glass-ceramics glazes; 3D image of the surface flaking for c) conventional and h) granulate onto glass-ceramic glazes; FESEM micrographs of the main damage for d) and e) conventional and i) and j) granulate onto glassceramic glazes.

Figure 5 a shows the optical image of the main damage produced in the conventional glaze where impact ring is formed with a total inner fragmentation of the ring $[7,22]$. The depth profile (figure $5 b$ ) reveals that the surface flaking width is $\approx 2246 \mu \mathrm{m}$, in agreement with FESEM micrograph of figure $4 \mathrm{~d}$, and the depth is $\approx 269 \mu \mathrm{m}$, which is approximately the thickness of the coating. Therefore, the impact produces the total flaking of the glaze coating, as shown in figure $5 \mathrm{a}$. In case of multilayered materials (as occurs in a glaze coating onto stoneware tile), the mechanical behavior is complex, since Hertzian and plastic behavior can coexist [23]. A 3D image of the surface flaking, figure 5c, shows that the maximum depth is located in the center of the impact (green region) and the depth is lower in the lateral regions, showing a conical shape corresponding to a Herztian cone [22]. An optical-profilometer image of a less prominent mark produced by the secondary ball bounces can be seen in figure S2a of the supporting information, which possess lower impact energy and, therefore, produce less damage, leaving a tiny circle imprint, in which an Herztian cone may also be produced [7]. For a further impact imprint analysis, at lower scale, FESEM analysis was carried out. The micrograph seen in figure $5 \mathrm{~d}$ (corresponding to the green square in figure $4 \mathrm{~d}$ ) shows that the ball impact produces a delamination of the conventional glaze coating, which reveals inner pores, having 20 - $45 \mu \mathrm{m}$ in width. Inside of some of these pores, residues of the fracture are accumulated and it is also possible to observe some chatter marks around the pore, indicating the friction direction (following the yellow arrow) as seen in figure S2b of supporting information, where it is also observed the gap left by some crystals that are ripped out during the impact test (marked with red arrows). In addition, in some damaged regions a delamination occurs at the interfaces between the vitreous matrix and the feldspar crystallizations, causing them to be exposed (red arrow), as observed in an enlarged micrograph in figure S2c of the supporting information. Figure $5 e$ (corresponding to blue square in figure $4 d$ ) shows magnified surface flaking produced by the ball rebound, where cracks appear around the contact point, as hackle marks (red arrows) [22]. These cracks possess some forking, which indicates moderate stress in the material.

In the case of the granulated glass-ceramic glaze, the ball impact produces several damages where the decorative motives have been removed and also present fractured impact ring, as seen in figure $5 f$. The depth profile (figure $5 \mathrm{~g}$ ) reveals that the width of the surface flaking is $\approx 1397 \mu \mathrm{m}$ and the depth is $\approx 150 \mu \mathrm{m}$. Therefore, despite the presence of granulate favors the damage generation in 
the glass-ceramic glaze coating, in which no damage is observed without granulate, the width and depth of the surface flaking is approximately $50 \%$ lower than the conventional coatings. Figure $5 \mathrm{i}$ shows an enlarged FESEM micrograph of the main surface flaking caused by the ball impact on granulated glass-ceramic coating (corresponding to green square in figure 4f), where it is observed that, in this case, the fracture is produced by delamination through the hierarchical glass-ceramic material. The pores of this material are smaller, 5 - $10 \mu \mathrm{m}$ in width, and less numerous than in the conventional glaze, therefore, their appearance after the impact does not suppose a threat to mechanical resistance. A short crack is observed in figure $5 f$ that is magnified in figure S2c of supporting information. This isolated and short crack $(I \leq 5 \mathrm{~mm}$, level 2$)$ does not present forking which indicates low impact stress. Finally, figure $5 \mathrm{j}$ shows a magnification of the damage area (blue square in figure 4f), where the gap left by some removed crystals is seen (red arrow). In this case, no fracture residues are observed.

In a homogeneous material, the ball impact produces a tensile stress in the contact surface between both objects and, when the critic load is achieved, the conical damage proportional to the applied load is produced. This behavior corresponds to the Hertzian mechanism. However, in a heterogeneous material with great amount of interfaces, which is the case that concerns us, the behavior is quite different. In this case, the maximum shear strain at the ball-surface contact is scattered in the deformation region and can produce a slight slump and some microcracks. If the applied load increases, these cracks can star to produce secondary cracks which would produce the damage [23-25]. This kind of behavior corresponds to a pseudo-plastic mechanism, in which, if the damage progresses, the material becomes detached. Therefore, the material's microstructure has an important influence in the impact resistance, so that homogeneous and heterogeneous materials follow mechanisms extremely different $[21,26]$.

As discussed, neither of the two damaged glazes present clear radial cracks around the imprint ring, which indicates that these materials have a quasi-plastic behavior. The damage internal area is totally fractured and/or only short radial cracks appear $[7,23,27]$. In case of the hierarchical glassceramic glaze, under the same conditions, it behaves as an elastic material since it is able to relax the generated mechanical stress and, therefore, no surface flaking is produced. These differences can be explained by the different microstructures, since they generate difference in density, porosity and number of interfaces, which are largely demonstrated to be key for mechanical properties.

According to these results, it is possible to extract some conclusions about the relationship between the microstructure and the impact resistance of materials. The hierarchical glass-ceramic material possesses great amount of interfaces due to its singular micro-nanostructure, since its presents 
feldspar microcrystals surrounded by nanocrystals of the same composition, with low amount of glassy phase (only $6 \%$ ), compared to the conventional glaze, as seen in figure $2[13,14]$. Since the shear stress may be relaxed through the grain boundaries, this distribution makes that the impact stress is greater relaxed due to the larger amount of the grain boundaries in this micronanostructure, reducing the damage probability. Moreover, other factor that affects the impact resistance is the grain size, so that higher the grain size, higher the damage produced for the impact because it decreases the grain boundary number $[25,26]$. As showed above, hierarchical glassceramic glaze possesses microcrystals more than 5 times smaller than conventional one, along to the presence of the nanostructure. Additionally, the glassy phase favors the crack propagation, especially if it constitutes a continuous phase in the microstructure. Therefore, the low content of glassy phase in the glass-ceramic regarding to the conventional glaze, also favors the damage inhibition. The porosity also affects the impact resistance, being higher when porosity size and proportion decreases.

In case of granulated glass-ceramic glaze, it was observed that impact damage is produced despite the unique microstructure of this material. Therefore, it is concluded that the roughness of the surface greatly affects the impact resistance $[20,21]$, since, when the roughness increases, the ball impacts in protruding parts, where all the stress load concentrates and the accumulated tension results in greater local damage. However, the impact damage is $\approx 50 \%$ lower than in the conventional glaze, due to the presence of the hierarchical layer that reduces the stress, and therefore reduces the damage.

\section{Conclusions}

The hierarchical nano-microstructure present in the developed glass-ceramic glaze is the main responsible factor of improving the mechanical properties of the conventional stoneware tiles, since both glazes possess similar chemical composition and thermal expansion coefficient. This nanomicrostructure favors higher stress relaxation by the larger amount of interfaces, lower porosity and less glassy phase that it possesses. These properties avoid the impact damages, keeping the resilience value. The application of this kind of glaze could suppose a great advantage in the ceramic field since the use of a hierarchical glass-ceramic coating can prevent from the damage in pavements, which expands its use in a large number of applications. Moreover, the hierarchical micro-nanostructured coating provides a new concept that could be applied to other ceramic materials in which the impact resistance is a critical parameter. 


\section{Acknowledgments}

The authors express their thanks to the MINECO (Spain) project MAT2017-86450-C4-1$\mathrm{R}$, and project CDTI of CTV for their financial support. Dra. E. Enriquez is also indebted to MINECO for a "Torres Quevedo" contract (ref: PTQ-14-07289), which is co-financed with European Social Funds.

\section{References}

[1] Specification for Glazed Ceramic Tiles and Tile Fittings for Internal Walls, British Standard, BS1281., (1966).

[2] R. Harrison, R. Brough, The impact resistance of ceramic tiles and flooring, in: Qualicer, Ceram Research, Stoke-on-Trent, UK, 1994: pp. 143-154.

[3] L. Li, L. Cheng, S. Fan, X. Gao, Y.P. Xie, L. Zhang, A novel fabrication approach for impact resistance laminated ceramics, Mater. Des. 79 (2015) 26-31. doi:10.1016/j.matdes.2015.04.043.

[4] C.Y. Huang, Y.L. Chen, Design and impact resistant analysis of functionally graded $\mathrm{Al}_{2} \mathrm{O}_{3}-$ $\mathrm{ZrO}_{2}$ ceramic composite, Mater. Des. 91 (2016) 294-305. doi:10.1016/j.matdes.2015.11.091.

[5] T.B. Da Cunha, J.P. Wu, O. Peitl, V.M. Fokin, E.D. Zanotto, L. lannucci, A.R. Boccaccini, Mechanical properties and impact resistance of a new transparent glass-ceramic, Adv. Eng. Mater. 9 (2007) 191-196. doi:10.1002/adem.200600237.

[6] C. Fragassa, F.V. de Camargo, A. Pavlovic, A.C. de F. Silveira, G. Minak, C.P. Bergmann, Mechanical characterization of gres porcelain and low-velocity impact numerical modeling, Materials (Basel). 11 (2018) 1-17. doi:10.3390/ma11071082.

[7] M. Dondi, G. Guarini, C. Melandri, M. Raimondo, C. Zanelli, Resistance to impact of porcelain stoneware tiles, Ceram. Int. 42 (2016) 5731-5736. doi:10.1016/j.ceramint.2015.12.104.

[8] M. Yasir, C. Zhang, W. Wang, Y. Jia, L. Liu, Enhancement of impact resistance of Febased amorphous coating by $\mathrm{Al}_{2} \mathrm{O}_{3}$ dispersion, Mater. Lett. 171 (2016) 112-116. doi:10.1016/j.matlet.2016.02.060.

[9] Q. Zhao, Y. Liang, Z. Zhang, X. Li, L. Ren, Effect of Al content on impact resistance 
behavior of $\mathrm{Al}-\mathrm{Ti}-\mathrm{B}_{4} \mathrm{C}$ composite fabricated under air atmosphere, Micron. 91 (2016) 1121. doi:10.1016/j.micron.2016.09.004.

[10] S. Ghosh, K.S. Pal, A.K. Mandal, N. Biswas, M. Bhattacharya, P. Bandyopadhyay, Cordierite based glass-ceramic glazed floor tiles by microwave processing, Mater. Charact. 95 (2014) 192-200. doi:10.1016/j.matchar.2014.05.023.

[11] Z. Wang, Y. Sun, H. Wu, C. Zhang, Low velocity impact resistance of bio-inspired building ceramic composites with nacre-like structure, Constr. Build. Mater. 169 (2018) 851-858. doi:10.1016/j.conbuildmat.2018.03.043.

[12] J.P. Best, M. Polyakov, D. Shinde, M.H. Colliander, J. Wehrs, J. Michler, M. Morstein, Ni nanocluster composites for enhanced impact resistance of multilayered arc-PVD ceramic coatings, Surf. Coatings Technol. 354 (2018) 360-368. doi:10.1016/j.surfcoat.2018.07.102.

[13] E. Enríquez, V. Fuertes, M.J. Cabrera, J. Seores, D. Muñoz, B. Galiana, J.F. Fernández, Study of the crystallization in fast sintered Na-rich plagioclase glass-ceramic, Ceram. Int. (2019) 0-1. doi:10.1016/j.ceramint.2019.01.219.

[14] V. Fuertes de la Llave, A. del Campo, J.F. Fernández, E. Enríquez, Structural insights of hierarchically engineered feldspars by confocal Raman microscopy, J. Raman Spectrosc. (2019) 1-14. doi:10.1002/jrs.5556.

[15] E. Enríquez, V. Fuertes, M.J. Cabrera, J. Seores, D. Muñoz, J.F.F. Fernández, New strategy to mitigate urban heat island effect : Energy saving by combining high albedo and low thermal diffusivity in glass ceramic materials, Sol. Energy. 149 (2017) 114-124. doi:10.1016/j.solener.2017.04.011.

[16] V. Fuertes, M.J. Cabrera, J. Seores, D. Muñoz, J.F. Fernández, E. Enríquez, Hierarchical micro-nanostructured albite-based glass-ceramic for high dielectric strength insulators, J. Eur. Ceram. Soc. 38 (7) (2018) 2759-2766. doi:10.1016/j.jeurceramsoc.2018.02.009.

[17] C. Fragassa, Limits in application of international standards to innovative ceramic solutions, Int. J. Qual. Res. 9 (2015) 279-298.

[18] F. Pacheco-Vázquez, S. Dorbolo, Rebound of a confined granular material: Combination of a bouncing ball and a granular damper, Sci. Rep. 3 (2013) 3-9. doi:10.1038/srep02158.

[19] R. Jankowski, Theoretical and experimental assessment of parameters for the non-linear 
viscoelastic model of structural pounding, J. Theor. Appl. Mech. 45 (2007) 931-942.

[20] W.L. Walters, Determination of impact resistance by measurement of coefficient of restitution, in: Qualicer, 1996: pp. 231-238.

[21] F. Orgaz, T.G. del Río, A. Varela, J. F. Fernández, Dynamic Mechanical Behaviour of Thick Alumina Layers with Thin Tunneled Interfaces, Ceram. Trans. 215 (2010) 27-40.

[22] T. Ono, R.A. Allaire, Fracture Analysis, A Basic Tool to Solve Breakage Issues, Taiwan FPD Expo 2000. (2004) 1-9.

http://www.new.corning.com/assets/0/391/2423/2437/2441/38FCE344-211C-454E-878C2BD1A9105453.pdf.

[23] G. Silva, A. Munoz, C. Felíu, V. Cantavella, Ceramic tile mechanical behaviour impact, Proc. Qualicer. IV World Congr. Ceram. Tile Qual. (2002) 385-399.

[24] B.R. Lawn, Indentation of Ceramics with Spheres: A Century after Hertz, J. Am. Ceram. Soc. 81 (2005) 1977-1994. doi:10.1111/j.1151-2916.1998.tb02580.x.

[25] B.A. Latella, T. Liu, A.J. Atanacio, Effect of grain size on Hertzian contact damage in 9 mol\% Ce-TZP ceramics, J. Eur. Ceram. Soc. 22 (2002) 1971-1979. doi:10.1016/S09552219(01)00527-1.

[26] A.R. Keller, M. Zhou, Effect of microstructure on dynamic failure resistance of titanium diboride/alumina ceramics, J. Am. Ceram. Soc. 86 (2003) 449-457. doi:10.1111/j.11512916.2003.tb03320.x.

[27] A. Ball, H.W. McKenzie, On the low velocity impact behaviour of glass plates, Le J. Phys. IV. 4 (1994) C8-783-C8-788. doi:10.1051/jp4:19948121. 